Research Article

\title{
Prevention Technology for Strong Mine Pressure Disaster in the Hard-Roof Large-Mining-Height Working Face
}

\author{
Hongfei Duan $\mathbb{D i D}^{1,2}$ and Lijuan Zhao $\mathbb{D}^{1}$ \\ ${ }^{1}$ School of Coal Engineering, Datong University, Datong 037003, Shanxi, China \\ ${ }^{2}$ Datong Coal Mine Group Co., Ltd., Datong 037003, Shanxi, China \\ Correspondence should be addressed to Lijuan Zhao; zhaolijuan115@126.com
}

Received 23 July 2020; Revised 4 September 2020; Accepted 30 September 2020; Published 22 October 2020

Academic Editor: Xianjie Hao

Copyright (C 2020 Hongfei Duan and Lijuan Zhao. This is an open access article distributed under the Creative Commons Attribution License, which permits unrestricted use, distribution, and reproduction in any medium, provided the original work is properly cited.

\begin{abstract}
The movement and destruction of the hard roof in a stope is an important reason for the occurrence of strong ground pressure disasters at the working face. Considering Tongxin Coal Mine as the engineering background, the stress distribution law of the surrounding rock and the overburden rock damage characteristics of a large-mining-height working face under the hard roof were investigated. To solve the problem whereby the stope's hard roof is difficult to collapse, the hard rock key stratum of the roof was hydraulically fractured to weaken the mechanical properties of the roof rock stratum. Additionally, microseismic monitoring technology was used to monitor the cracking effect of the rock stratum. The theoretical calculation and numerical simulation results reveal that, after hydraulic fracturing, a crack with a more consistent trend formed inside the hard rock stratum and a large area of the rock stratum was damaged. According to the monitoring results of the stope stress after hydraulic fracturing, the law governing the occurrence of the leading bearing pressure was in effect. In contrast, the influence range and peak strength of the leading bearing pressure were considerably reduced at the working face after hydraulic fracturing. After performing hydraulic fracturing on the roof of the working face, the bearing pressure of the working face can satisfy the production requirements better. Finally, the results obtained through this study can be used as a reference for determining the width of coal pillars under similar mining conditions.
\end{abstract}

\section{Introduction}

In China, coal is a primary energy source. The proven coal reserves amount to 1.34 trillion tons, $44 \%$ of which are buried in 6-20 $\mathrm{m}$ super-thick coal seams. Each year, the output from underground thick coal seams accounts for over $45 \%$ of the total coal output in China $[1,2]$. Driven by the research and application of technologies for large-miningheight fully mechanized caving, the annual output from super-thick coal seams has reached 10 million tons [3-5]. However, with the increase of the mining height, the overburden movement and stress concentration effects caused by coal seam mining are increasingly becoming obvious and are accompanied by several accidents, such as roof collapse, coal-seam gas outburst, and rock burst [6-8], which pose severe threats to mining safety.
To identify the rules of strong ground pressure behaviors in super-thick coal seam mining, many scholars have conducted extensive research using theoretical analyses, field measurements, similarity modeling, and numerical simulations, achieving fruitful results [9-11]. By investigating the roof movement rules of the large-mining-height fully mechanized caving faces of the 5\# coal seam in Aiweiergou Coal Mine of Xinjiang, Wu et al. [12] discovered that the mine pressure of working faces has varying magnitude, and they introduced a similarity simulation experiment for verification and inversion, explored the abutment pressure change rules in front of working faces and the mechanical mechanism of roof cutting, and analyzed the correlation between lead abutment pressure change rules and roof weight. Wang [13, 14] performed a mechanical analysis and experimental study with regard to the occurrence of 
"two-hard" large-mining-height coal seams, built an elastic thin-plate mechanics model for first roof caving, probed the characteristics of the segmented weighting of roof strata in different zones along face length, analyzed the cause of weight transfer in roof strata, compared mine pressure characteristics and differences among different zones in working faces, and identified the reasons for differences in roof weight intensity in different zones. Focusing on abutment pressure distribution in the super-thick alluvia of coal mines with strong rock bursts, Zhu et al. [15] explored the abutment pressure load transfer mechanism based on the key stratum theory, surveyed Xinjulong Coal Mine using stress and microseismic monitoring, and verified model rationality. In order to solve the problems of large-scale disturbance fracturing and intense strata behaviors caused by thick coal seam mining, Yang et al. $[16,17]$ performed a theoretical analysis and large-scale laboratory simulation experiments to investigate the influence of the large-miningheight slicing of thick coal seams on the overburden movement and mine pressure in thick coal seams.

Most of the above-mentioned studies focused on the roof rock structure and its migration law and investigated the mechanical mechanism of roof migration in large-miningheight coal seams. In previous studies, the analysis of the correlation between the change of the lead abutment pressure and roof movement and the proposal of appropriate technical measures against the characteristics of largemining-height coal seam pressure were dramatic and the impact range was large [18-22]. However, previous studies have failed to actively investigate the law governing roof stratum structures and the abutment pressure behavior or propose targeted measures to modify the roof strata properties.

This study considered Tongxin Coal Mine as the research background because it has a typical hard roof and large-mining-height coal seam. A numerical simulation method was used to investigate the stress distribution law of the surrounding rock in the stope under the hard roof condition. Additionally, the distribution law and stress characteristics of the surrounding rock in the stope were determined. The hydraulic fracturing method was used to weaken the roof rock stratum to actively control the rock stratum destruction and reduce the stress of the stope's surrounding rock. To effectively evaluate the effect of hydraulic fracturing, the real-time monitoring of the fracturing process was combined with microseismic monitoring technology. This paper proposes a method for preventing strong mine pressure disasters occurring in a stope with a hard roof. The results obtained by this study can be useful as a reference in the development of hydraulic fracturing technology for the fracturing and weakening of hard rock stratums.

\section{Influence of Hard Key Stratum on Mine Pressure}

2.1. Numerical Simulation Modeling. To determine the influence of hard roof on the stress distribution of surrounding rock around the stope, the numerical simulation was used to study the stress distribution of surrounding rock. The finite difference software FLAC3D is used to simulate face mining, thus laying a foundation for the next step.

A numerical simulation model was built according to the actual conditions of the 8309 working face, as shown in Figure 1. The model is $600 \mathrm{~m} \times 400 \mathrm{~m} \times 300 \mathrm{~m}$ (length $\times$ width $\times$ height) in size, and all of its boundaries (except top boundary) are subject to normal constraints. Because of the large strength of the basic roof and its decisive role in overburden movement, basic roof strata are simplified to be strata with the same lithology. Similarly, the rock mass under the floor mudstone is simplified to have the same lithology. Based on burial depth and overburden density, an equivalent vertical load of 7.6 MPa is applied at the top. In the numerical simulation model, the physical and mechanical parameters of various strata are selected based on laboratory data. See the physical and mechanical parameters of various strata and coal mass in Table 1.

After the initial stress field is balanced, the intake and return air roadways are first excavated according to the actual roadway size, and then the coal seam is simulated. The excavation step distance of coal seam is set as $10 \mathrm{~m}$. The whole height of coal seam is directly excavated once in each step to simulate the huge empty area formed after top coal caving mining. After the next step of excavation, gangue backfill simulation is carried out immediately for the previous excavation. There are 30 excavation steps in the whole coal seam, and the advance along the strike direction is $300 \mathrm{~m}$.

\subsection{Abutment Pressure Distribution in Coal Seams.}

Affected by face advance distance, the influence scope and peak intensity of lead abutment pressure constantly varies. Figure 2 shows the abutment pressure distribution during face mining at different face advance distances, i.e., $100 \mathrm{~m}$, $150 \mathrm{~m}, 200 \mathrm{~m}$, and $300 \mathrm{~m}$.

As can be seen from Figure 2, the advance of the working face breaks the rock mass equilibrium around the stope, and the gravitational force of the overburden in the goaf shifted to the peripheral coal mass, resulting in stress concentration. Within a certain range near the stope, the vertical stress in coal mass significantly increases, producing an abutment pressure; however, the increase in vertical stress was not infinite, as, after reaching a certain degree, it gradually decreased to original rock stress. In front of the working face, abutment pressure first increased and then decreased, forming three zones, i.e., the original rock stress zone, increasing stress zone, and decreasing stress zone. Because of the large overburden strength and stop thickness, stability could still be maintained after the working face advanced a certain distance. With increasing excavation distance, the abutment pressure influence scope and peak intensity gradually increased.

2.3. Lead Abutment Pressure Distribution Rules. Since the distribution of the front abutment pressure and the side abutment pressure are similar, select the front abutment pressure as the research object. To determine the lead abutment pressure change rules in the coal mass, the abutment pressures in front of the coal wall at face advance 


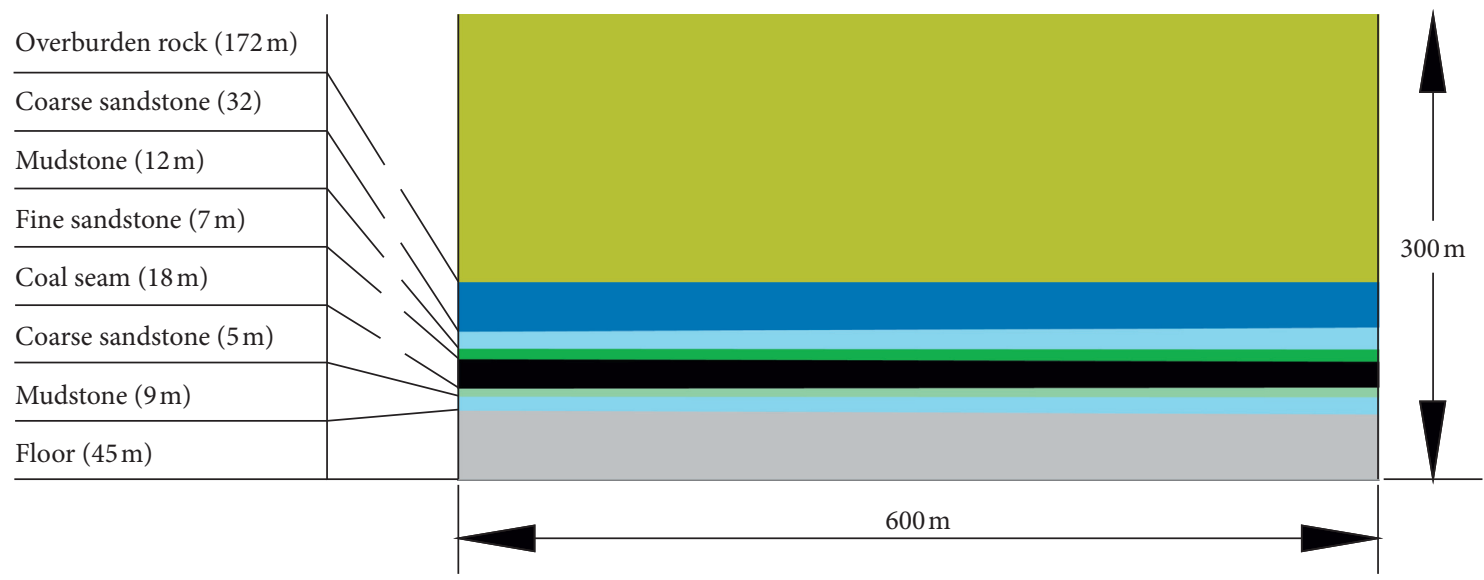

Figure 1: Numerical simulation model.

Table 1: Physical and mechanical parameters of various strata.

\begin{tabular}{|c|c|c|c|c|c|c|}
\hline Stratum & $\begin{array}{c}\text { Density } \\
\left(\mathrm{kg} \cdot \mathrm{m}^{-3}\right)\end{array}$ & $\begin{array}{c}\text { Bulk modulus } \\
(\mathrm{GPa})\end{array}$ & $\begin{array}{c}\text { Shear modulus } \\
(\mathrm{GPa})\end{array}$ & $\begin{array}{l}\text { Cohesive force } \\
(\mathrm{MPa})\end{array}$ & $\begin{array}{c}\text { Internal friction } \\
\text { angle }\left({ }^{\circ}\right)\end{array}$ & $\begin{array}{c}\text { Tensile strength } \\
(\mathrm{MPa})\end{array}$ \\
\hline Overburden & 2400 & 9.33 & 5.60 & 5.5 & 35 & 3.0 \\
\hline Sandstone grit & 2400 & 12.68 & 8.73 & 6.8 & 35 & 5.5 \\
\hline Mudstone & 2400 & 3.1 & 3.5 & 5.0 & 40 & 1.5 \\
\hline Sandy mudstone & 2300 & 10.95 & 7.54 & 5.0 & 33 & 4.2 \\
\hline Fine sandstone & 2500 & 18.49 & 15.04 & 15.7 & 40 & 9.2 \\
\hline Coal seam & 1400 & 1.95 & 1.31 & 4.2 & 38 & 1.3 \\
\hline Floor & 2400 & 11.83 & 8.88 & 8.5 & 35 & 6.0 \\
\hline
\end{tabular}

distances of $50 \mathrm{~m}, 150 \mathrm{~m}$, and $250 \mathrm{~m}$ are selected for investigation. Figure 3(a) shows the lead abutment pressure change curves.

As can be seen from Figure 3(a), lead abutment pressure can be divided into three zones: the decreasing stress zone (AB segment: 0-10 m), increasing stress zone (BC segment: 10-73 m), and original rock stress zone (CD segment: above $73 \mathrm{~m}$ ). Within segment $A B$, lead abutment pressure gradually increased with increasing distance from the coal wall, and, when the distance from the coal wall increased to $10 \mathrm{~m}$, the abutment pressure concentration coefficient reached its peak. Within segment BC, lead abutment pressure declined with increasing distance from the coal wall, and its curve gradually tended to be gentle. Within segment CD, the lead abutment curve pressure was gentle, and, in particular, when the working face advanced by $50 \mathrm{~m}$, the abutment pressure concentration coefficient stabilized around 1.0; however, at face advance distances of $150 \mathrm{~m}$ and $250 \mathrm{~m}$, the abutment pressure concentration coefficient curves still gradually declined and approached 1.0 .

It can be seen from Figure 3(b) that with increasing face advance distance, the abutment pressure concentration coefficient in front of the working face began to increase but did not exert any influence on the peak lead abutment pressure position. Taking lead abutment pressure coefficient peak as an example, when the working face advanced by $50 \mathrm{~m}$, peak concentrated stress was 1.41 and was located $10.1 \mathrm{~m}$ in front of the working face. When advance distance increased to $150 \mathrm{~m}$ and $250 \mathrm{~m}$, peak concentrated stress increased to 1.7 and 1.81 , respectively and was still located $10.1 \mathrm{~m}$ in front of the working face.

2.4. Influence Scope of Lead Abutment Pressure. After excavation reaches equilibrium each time, the abutment pressure concentration coefficient in front of the working face is determined, and the region where the abutment pressure coefficient is greater than 1.2 is defined as the abutment pressure influence scope. See its correlation with face advance distance in Figure 4.

As can be seen from Figure 4, the change in abutment pressure influence scope can be divided into the growth and stabilization stages. When face advance distance increased from $10 \mathrm{~m}$ to $210 \mathrm{~m}$, abutment pressure influence scope in front of the coal wall increased continuously and reached its peak of $68.1 \mathrm{~m}$ at a face advance distance of $210 \mathrm{~m}$. When face advance distance exceeded $210 \mathrm{~m}$, abutment pressure influence scope stabilized at approximately $65 \mathrm{~m}$.

2.5. Breaking of Face Roof Strata. The numerical simulation model can satisfactorily present the overburden failure process during mining. To quantitatively analyze overburden breaking as the working face advances, the built-in fish language of FLAC3D is used to continuously monitor element failure for each excavation step. When a stratum experiences plastic failure, it can be held that this stratum has fractured; when a stratum experiences full plastic zone 
Zone YY stress

Cut plane: on

Calculated by: volumetric averaging

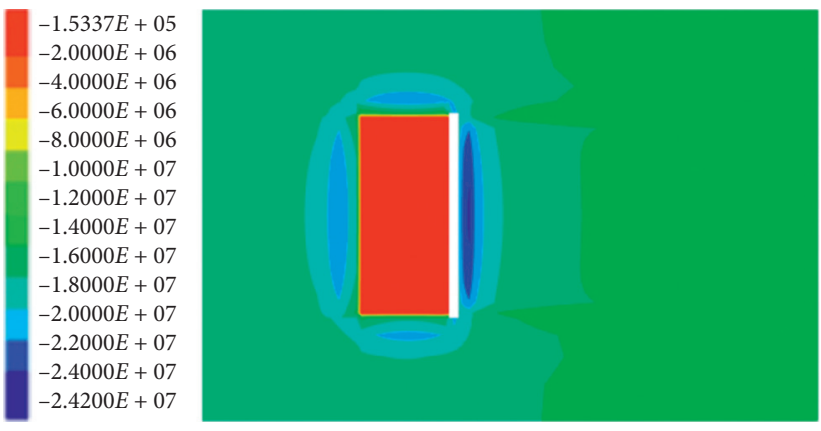

(a)

Zone YY stress

Cut plane: on

Calculated by: volumetric averaging

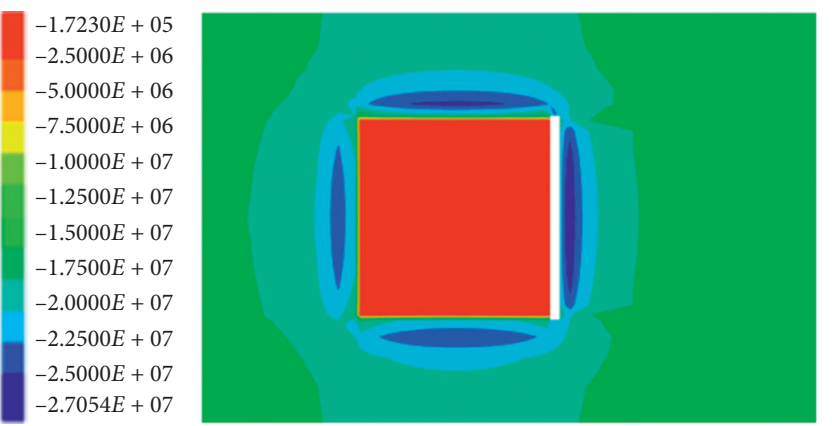

(c)
Zone YY stress

Cut plane: on

Calculated by: volumetric averaging

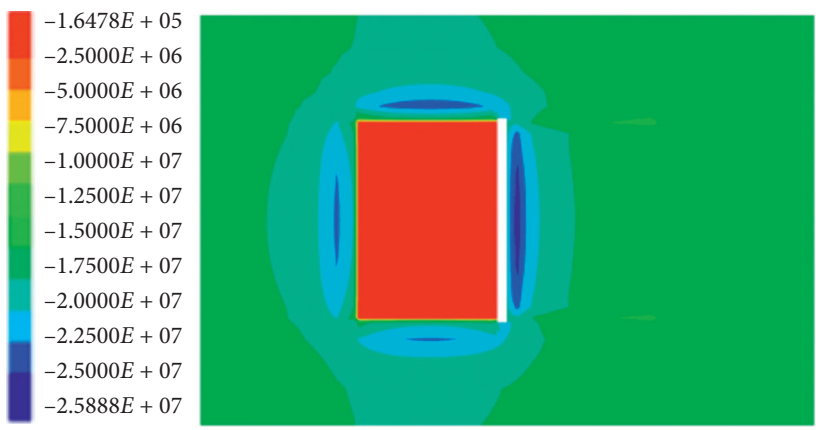

(b)

Zone YY stress

Cut plane: on

Calculated by: volumetric averaging

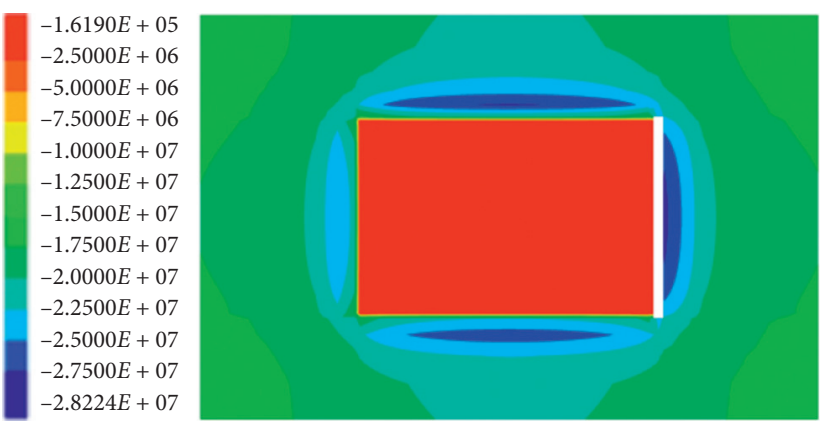

(d)

Figure 2: Abutment pressure distribution during face mining at different distances. (a) Advanced $100 \mathrm{~m}$. (b) Advanced $150 \mathrm{~m}$. (c) Advanced $200 \mathrm{~m}$. (d) Advanced $300 \mathrm{~m}$.

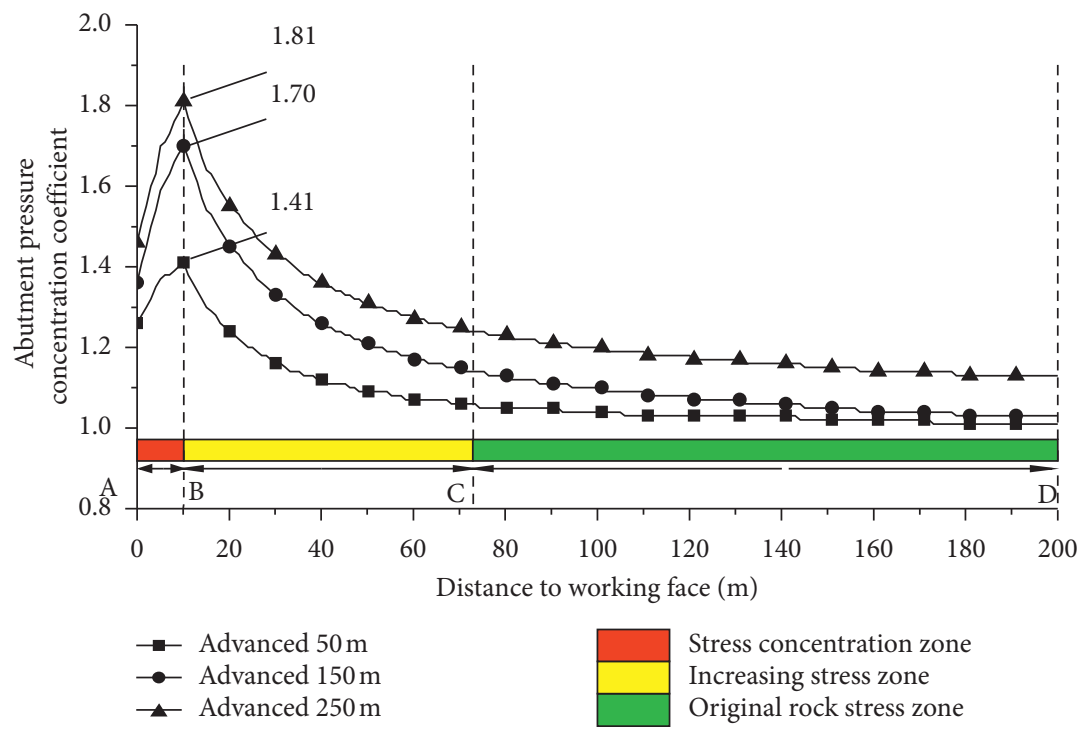

(a)

Figure 3: Continued. 


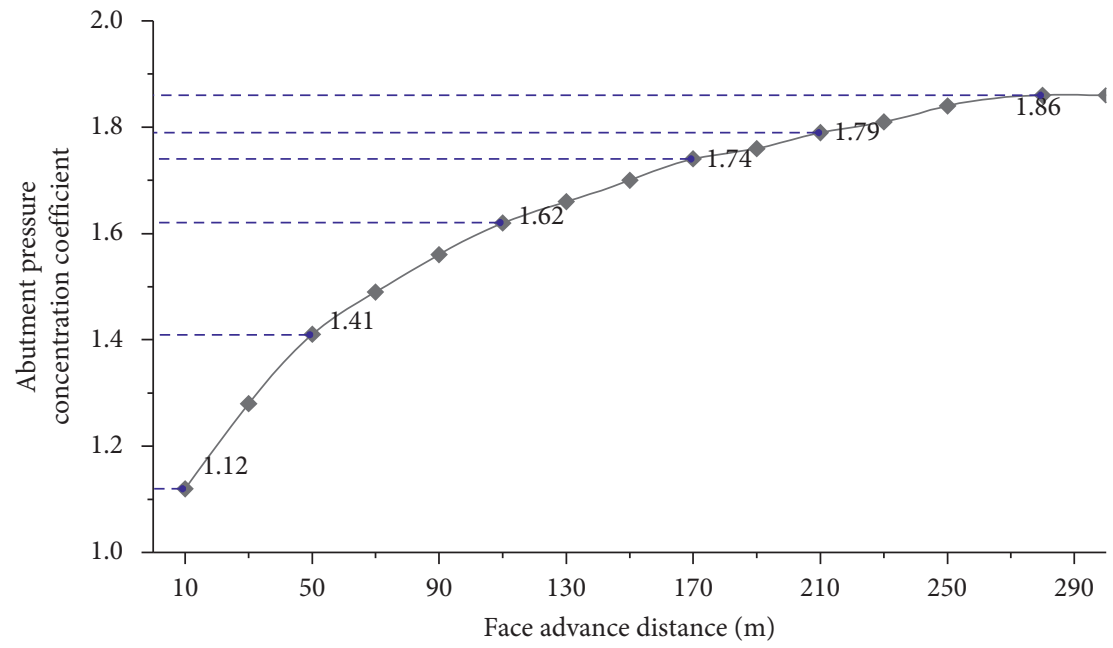

(b)

FIgURE 3: Variation law of abutment pressure. (a) Abutment pressure concentration coefficients in front of coal wall. (b) Change in abutment pressure concentration coefficient with face advance.

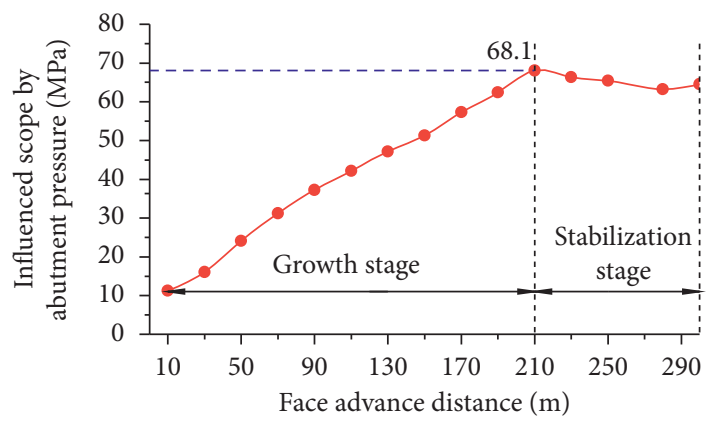

FIGURE 4: Diagram of abutment pressure influence range with working face advancement.

connection, it can be held that this stratum has completely broken. Figure 5 shows the cloud map of the plastic zone in different excavation stages. Figure 6 shows the maximum overburden failure height for each excavation step (the coalseam bottom level is set as $0 \mathrm{~m}$ elevation).

As can be seen from Figures 5 and 6, when face advance distance was $30 \mathrm{~m}$, the immediate roof experienced its first tensile failure and began to cave, and the maximum overburden failure height was $18 \mathrm{~m}$. When face advance distance was $70 \mathrm{~m}$ (Figure 5(a)), the immediate roof experienced its first caving due to tensile failure in which case the upper mudstone experienced plastic-slip shear failure due to immediate roof caving. Because of caving of the lower immediate roof and the aggravated failure of the mudstone, a local small-scale failure occurred in the main roof, and the maximum overburden failure height increased to $43.7 \mathrm{~m}$. Later, the immediate roof and overlying mudstone began to experience stable stability failure, and the maximum overburden failure height began to slowly increase. The pace of main roof failure increased significantly until the working face advanced to $210 \mathrm{~m}$ (Figure 5(b)) in which case the main roof first broke due to penetrating shear failure and the maximum overburden failure height increased to $86.2 \mathrm{~m}$.
After that, the main roof began its periodical failure, and the maximum overburden failure height also tended to be stable (Figure 5(c)).

As can be seen from the above analysis, because of the inadequate caving of the immediate roof and main roof, the roof had a large hanging area during the first caving, which further resulted in a high lead abutment pressure, wide influence scope, lead abutment difficulties, and other problems. In combination with abutment pressure change rules, it can be known that, when the immediate roof and basic roof of a stope break, the lead abutment pressure of the stope enters a stable state. Thus, taking proper measures to weaken roof strata and accelerate breaking of the immediate roof and main roof in mining is conductive to reducing the intensity of lead abutment pressure behaviors.

\section{Hydraulic Fracturing Test of Hard Roof}

According to previous research studies, the reason for the occurrence of strong mine pressure disasters in Tongxin Mine is that the roof of coal seams \#3-5 are covered with a thick and high-strength sandstone layer. When the fracture area of the goaf roof is not large, the lead abutment pressure is obvious, and the stope's concentration factor is large, which poses a severe threat to the safety of mining production. To solve this problem, a ground hydraulic fracturing test was conducted. The integrity of the hard roof was disturbed to cause full collapse and reduce the pressure intensity of the working face and side roadways.

A hydraulic fracturing field test was conducted at Tashan Coal Mine in the Datong mining area. The test working face is the 8202 working face, and the cracking well number is TXZL-01. The 8202 working face is located in panel 2 . Above the working face, there are mined-out Jurassic coal seam areas, and the lower part is located at the distance of 105-185 $\mathrm{m}$ from the No. 14 coal seam. 
None

Shear-n shear- $p$

Shear- $p$

Tension-n tension- $p$

Tension- $p$

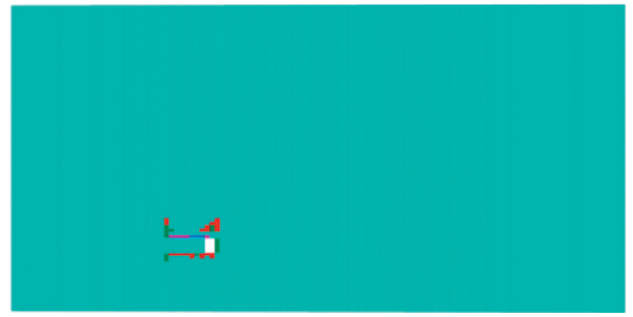

(a)

None

Shear-n shear- $p$

Shear- $p$

Shear- $p$ tension- $p$

Tension- $\mathrm{n}$ shear- $p$ tension- $p$

Tension- $n$ tension- $p$

Tension- $p$

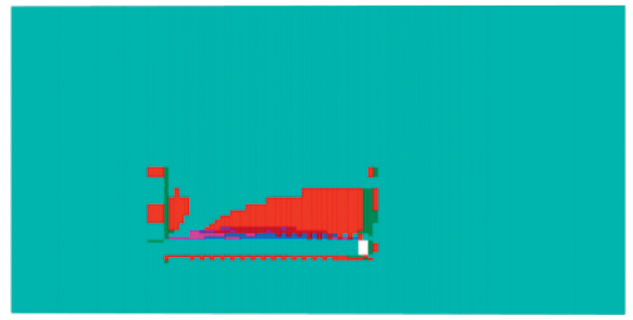

(b)

None

Shear-n shear- $p$

Shear- $p$

Shear-p tension- $p$

Tension- $n$ shear- $p$ tension- $p$

Tension- $n$ tension- $p$

Tension- $p$

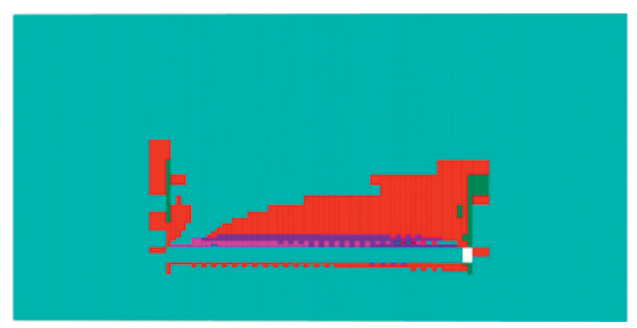

(c)

FiguRE 5: Overburden failure with working face advancement. (a) $70 \mathrm{~m}$ has been excavated. (b) $210 \mathrm{~m}$ has been excavated. (c) $300 \mathrm{~m}$ has been excavated.

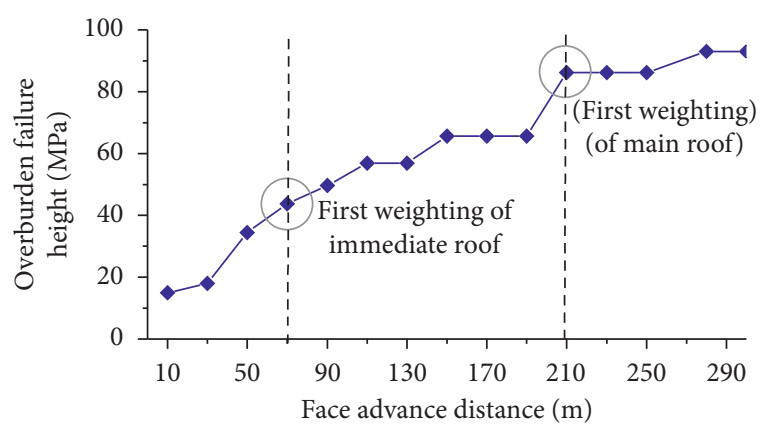

Figure 6: Change of maximum overburden failure height with face advancement.

Ground drilling and fracturing technology can weaken the overall strength of the rock mass. The main function has two aspects, which are reflected as follows: first, through the chemical dissolution of the acid on the rock to reduce the rock's mechanical properties; and second, through the generation and expansion of hydraulic cracks, whereby the macro and meso structure of the rock body is transformed to reduce the mechanical properties of the rock body. The two aspects work together to weaken the mechanical properties of the rock mass and reduce the overall strength of the roof rock. This promotes the collapse of the roof over time and prevents the roof from collapsing and releasing energy in a concentrated manner.
3.1. Hydraulic Fracturing Scheme. The cracks produced by hydraulic fracturing are typically centered on the borehole. The cracks in the principal stress direction are longer, while the cracks in the vertical principal stress direction are shorter. Therefore, hydraulic fracturing wells are deployed in the middle of the face. The width of the test working face is $251 \mathrm{~m}$. The first hydraulic fracturing well is approximately $125 \mathrm{~m}$ away from the roadway on both sides of the working face, and approximately $58 \mathrm{~m}$ away from the setup entry. The impact range of the surface well fracturing is approximately $100-150 \mathrm{~m}$. Therefore, the hole spacing is $200-300 \mathrm{~m}$. The relative positional relationship of the TXZL-01 and 8202 working faces in the fractured wells is shown in Figure 7.

The drill holes near the test face are drill holes \#1601, \#1602, \#1704, \#1508, \#1703, and so on. According to the drilling data, only the drill hole \#1508 has integral coring, while the rest of the holes are not cored. Therefore, the cracking target layer design is only based on histogram \#1508 (Figure 8).

By comparing and analyzing the rock stratum in the range of $0-80 \mathrm{~m}$ above coal seams $\# 3-5$, the fracturing target layer was determined as follows:

(1) Medium granular sandstone with a thickness of $13.7 \mathrm{~m}$ at a distance of $78.5 \mathrm{~m}$ from coal seams \#3-5.

(2) Microconglomerate with a thickness of $12 \mathrm{~m}$ at a distance of $66.5 \mathrm{~m}$ from coal seams \#3-5. 


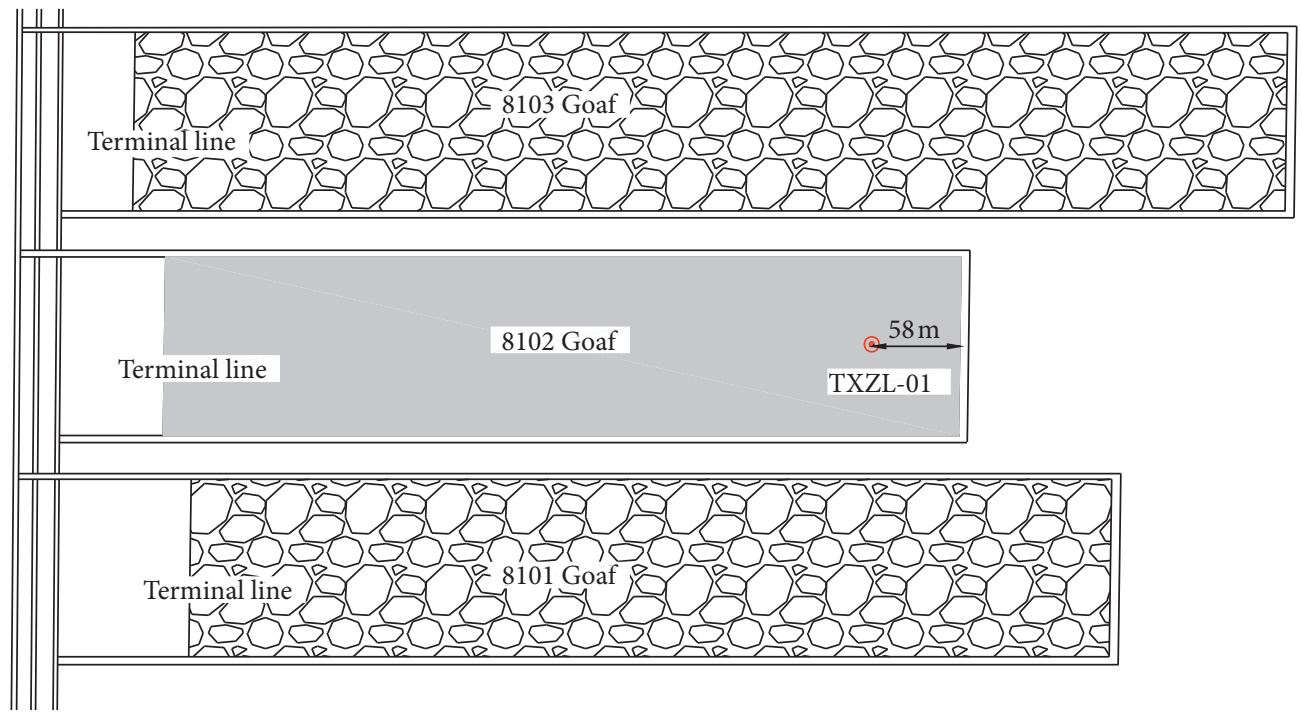

FIGURE 7: Relationship between fractured well and working face.

(3) Pebblestone with a thickness of $8.53 \mathrm{~m}$ at a distance of $50.2 \mathrm{~m}$ from coal seams $\# 3-5$.

3.2. Shaft Structure. Drilling work is divided into three times, and the overall structure of the fracturing well is shown in Figure 9.

3.2.1. First Drilling. The $\mathrm{D} 425 \mathrm{~mm}$ drill bit was used to drill through the loess formation and aerated layer on the surface and finally reached $10 \mathrm{~m}$ below the basal complex. The surface casing with a lower outer diameter of $377.7 \mathrm{~mm}$ was at a distance of $0.5 \mathrm{~m}$ from the bottom of the hole. If cement with conventional density is used to strengthen the well, the cement returns to the surface.

3.2.2. Second Drilling. First, a $311.15 \mathrm{~mm}$ drill bit was used to drill through the floor of the Jurassic goaf down to $22 \mathrm{~m}$. A $244.5 \mathrm{~mm}$ sleeve was inserted. The bottom exit of the casing was reinforced with cement, and the cement returned to the goaf floor.

3.2.3. Third Drilling. A $215.9 \mathrm{~mm}$ drill bit was used to drill through the roof of coal seams \#3-5. Casing with a diameter of $139.7 \mathrm{~mm}$ was inserted. Conventional density cement was used to strengthen the well, and the cement returned to the distance of $200 \mathrm{~m}$ above the target layer.

3.3. Nitrogen Drilling Technology. During drilling, the TXZL-01 well must pass through the Jurassic coal goaf. Compared with conventional drilling, the most significant construction difficulty in drilling through a goaf is the loss of drilling fluid, for which normal circulation cannot be established. To overcome the effect of drilling fluid loss, air was used as the circulating medium during the second drilling to ensure the success rate of the drilling construction.
The use of air as a drilling medium has many advantages. Using air as a medium can substantially increase the drilling speed. However, the density and pressure on the wellhead are low. During the drilling process, there is no drilling fluid leakage; thus, the leakage problem of complex formation drilling is effectively solved, which greatly reduces the loss and accelerates the drilling progress. Moreover, air drilling has important shortcomings, and the phenomenon of sending air into the goaf is observed during construction.

To avoid safety problems in the process of drilling through the goaf, nitrogen is used as the drilling medium to prevent the spontaneous combustion of coal in the area and to eliminate the risk of gas explosion.

3.4. Hydraulic Sandblasting Perforation and Fracturing. According to the construction requirements, the compounding fracturing method of acid treatment and sand fracturing was adopted. The principle of hydraulic sand fracturing technology entails the use of a sand-carrying highpressure prefluid to penetrate the casing, cement ring, and formation and perform fracturing or acidizing. The advantage of this approach is that there is no need for separate perforation and direct sandblast fracturing to complete the perforating fracture operation. Instead, only one pipe string is required to perform the multilayer perforation and fracturing operation, and the perforation and fracturing are completed simultaneously.

The key stratum of the working face is sandstone; therefore, a large amount of acid is added to the front liquid. The acid mainly consists of hydrochloric acid (HCL) and hydrofluoric acid (HF). The HCL reacts with the cement in sandstone, and the HF reacts with the silicate in sandstone. Thus, the chemical weakening of the key stratum is realized. After the mud acid injection, the pump is stopped, and after a certain period of time, a large amount of fracturing fluid is injected into the key stratum for hydraulic fracturing. The fractures produced by hydraulic fracturing break the key 


\begin{tabular}{|c|c|c|c|c|c|c|c|c|c|}
\hline Histogram & Number & $\operatorname{Depth}(\mathrm{m})$ & $\begin{array}{c}\text { Thick- } \\
\text { ness (m) }\end{array}$ & $\begin{array}{l}\text { Length } \\
(\mathrm{m})\end{array}$ & $\begin{array}{c}\begin{array}{c}\text { Adoption } \\
\text { rate }\end{array} \\
\end{array}$ & Inclination & $\begin{array}{c}\text { Grand } \\
\text { total }(\mathrm{m})\end{array}$ & $\begin{array}{l}\text { Rock } \\
\text { name }\end{array}$ & Remarks \\
\hline & & 363.32 & 10.72 & 10.25 & 96 & & 363.26 & Micropsammite & \\
\hline- & & 366.50 & 3.18 & 3.15 & 99 & & 366.44 & Aleurolite & \\
\hline & & 380.20 & 13.70 & 13.05 & 95 & & 380.14 & Pebbly sandstone & $\begin{array}{l}\text { Fractured rock } \\
\text { formation }\end{array}$ \\
\hline E & & 392.20 & 12.00 & 9.88 & 82 & & 392.14 & Microconglomerate & $\begin{array}{l}\text { Fractured rock } \\
\text { formation }\end{array}$ \\
\hline$\because$ & & 395.65 & 3.45 & 3.25 & 94 & & 395.59 & Kernstone & \\
\hline$\infty_{\infty \infty \infty}^{\infty}$ & & 399.97 & 4.32 & 4.30 & 100 & & 399.91 & Microconglomerate & \\
\hline & K8 & 408.50 & 8.53 & 1.90 & 22 & & 408.44 & $\begin{array}{l}\text { Medium-grained } \\
\text { sandstone }\end{array}$ & $\begin{array}{l}\text { Fractured rock } \\
\text { formation }\end{array}$ \\
\hline$=$ & & 409.07 & 0.57 & 0.50 & 88 & 4 & 409.01 & Aleurolite & \\
\hline 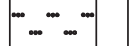 & & 412.57 & 3.50 & 3.35 & 96 & & 412.51 & Micropsammite & \\
\hline 1. & & 416.37 & 3.80 & 3.70 & 97 & & 416.31 & Kernstone & \\
\hline$\because \ldots$ & & 417.39 & 1.02 & 1.00 & 98 & & 417.33 & Pebbly sandstone & \\
\hline & & 423.29 & 5.90 & 5.65 & 96 & & 423.23 & Micropsammite & \\
\hline - & & 427.59 & 4.30 & 4.25 & 99 & & 427.53 & Kernstone & \\
\hline in & & 427.84 & 0.25 & 0.25 & 100 & & 427.78 & Arenaceous mudstone & \\
\hline- & & 430.02 & 1.98 & 1.65 & 83 & & 429.96 & Aleurolite & \\
\hline & & 432.12 & 2.10 & & & & 432.06 & Shan4Coal & \\
\hline- & & 433.68 & 1.56 & 1.49 & 96 & & 433.62 & Aleurolite & \\
\hline & & 434.00 & 0.32 & 0.30 & 94 & & 433.94 & Carbon mudstone & \\
\hline- & & 437.40 & 3.40 & 3.15 & 93 & & 437.34 & & \\
\hline$-\infty$ & & 439.50 & 2.10 & 2.00 & 95 & & 439.44 & Micropsammite & \\
\hline$\because \ldots$ & & 442.00 & 2.50 & 2.35 & 94 & & 441.94 & Pebbly sandstone & \\
\hline$\because \because$ & & 445.17 & 3.17 & 3.10 & 98 & & 445.11 & Kernstone & \\
\hline$\ldots \ldots$ & & 447.50 & 2.33 & 2.25 & 97 & & 447.44 & Pebbly sandstone & \\
\hline$\because \because$ & K3 & 450.00 & 2.50 & 2.25 & 90 & & 449.94 & Kernstone & \\
\hline$\ldots \ldots$ & & 450.95 & 0.95 & 0.73 & 77 & 4 & 450.89 & Micropsammite & \\
\hline- & Coal seam \#1 & 451.25 & 0.30 & 0.30 & 100 & & 451.19 & 1\# Coal seam & \\
\hline (-..- & & 452.01 & 0.76 & 0.75 & 99 & & 451.95 & Aleurolite & \\
\hline 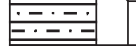 & & 454.04 & 2.03 & 1.95 & 96 & 4 & 453.98 & Arenaceous mudstone & \\
\hline$-\ldots$ & Coal & 454.30 & 0.26 & 0.26 & 100 & & 454.24 & Coal & \\
\hline 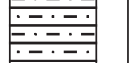 & & 456.69 & 2.39 & 2.19 & 92 & & 456.63 & Arenaceous mudstone & \\
\hline & 2\# Coal & 457.49 & 0.80 & 0.80 & 100 & & 457.43 & 2\# Coal seam & \\
\hline$-\cdots$ & & 458.70 & 1.21 & 1.19 & 98 & & 458.64 & Arenaceous mudstone & \\
\hline & Coal seam \#3-5 & 477.30 & 18.6 & 2.13 & 97 & & 477.24 & 3-5\# Coal seam & \\
\hline
\end{tabular}

FIgURE 8: Location map of the cracking target layer. 


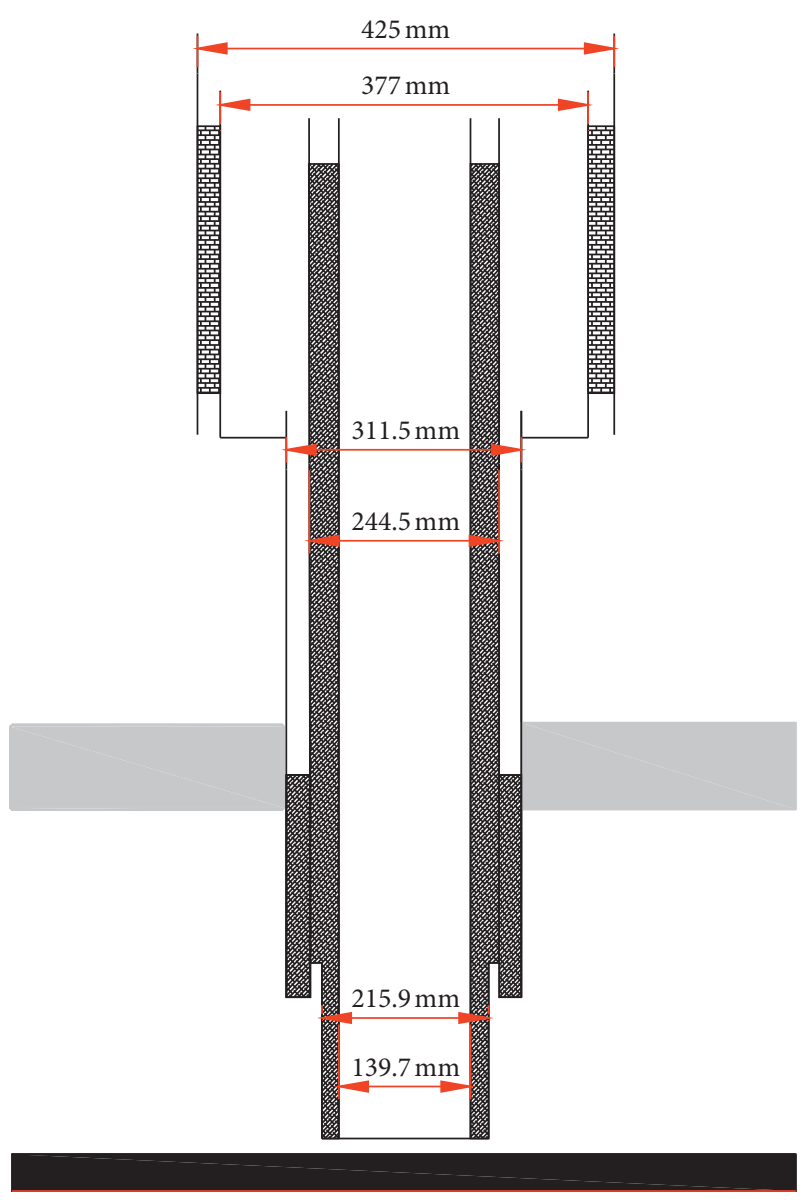

FIGURE 9: Schematic diagram of the fractured well structure.

stratum, reduce the stress concentration of the key stratum, and prevent rock bursting through physical damage. To enhance the fracturing effect and contribute to fracture extension, fine sand is added as the supporting agent in the fracturing construction. On one hand, the use of fine sand can reduce the liquid filtration and improve the liquid efficiency. On the other hand, fine sand can grind the crack wall, which reduces the production of bending cracks and is beneficial to the production of long cracks. To improve the effect of compound fracturing, the well is fully shut in without blowout after fracturing to provide sufficient time for the acid-rock reaction and full weakening of the key stratum.

\section{Microseismic Surface Monitoring}

4.1. Seismic Crack Monitoring Technology. To test the fracturing effect, microseismic monitoring was carried out for the fracturing process. Since the 1970s [23, 24], microseismic monitoring technology has been extensively investigated and applied domestically and abroad. This technology has achieved many practical results in production and can be used to monitor the shape of the fracture space, effective fracture length, fracture height, and in situ stress distribution of the fracturing well. Additionally, it facilitates an ideal fracturing process, evaluates the fracturing effect, performs postfracturing productivity analysis on the fracturing well, and provides a satisfactory pattern layout and strong basis. Artificial microseismic real-time monitoring is also based on this technology and uses the microearthquakes generated during fracturing, the on-site monitoring system, and the computer with a corresponding expert interpretation system to interpret and analyze on-site monitoring data in real time.

Microseismic monitoring is currently the most accurate, timely, and informative monitoring method for hydraulic fracturing. Real-time microseismic imaging can guide a fracturing project over time and adjust the fracturing parameters in a timely manner. The comprehensive analysis of the fracturing parameters and source parameters can track and locate the range of fracturing and the direction and size of fracture development and objectively evaluate the effect of fracturing projects.

4.2. Monitoring Program. The fracturing end points of each fracturing layer are calculated according to the fracture design scheme, by focusing on its ground projection and arranging geophones based on the surrounding topography (with the wellhead as the center). The microseismic test station and equipment are shown in Figure 10. The relative positions of the TXZL-01 well and \#1-6 geophones in the test drilling are shown in Figure 11.

The geophone positioning and embedding requirements are as follows:

(1) The detector must be accurately positioned using a high-precision global positioning system (GPS; accuracy not greater than $1.0 \mathrm{~m}$ ).

(2) The buried depth of the detector is not less than $0.2 \mathrm{~m}$.

4.3. Microseismic Monitoring Results. The microseismic specimens of each rock stratum were monitored during the hydraulic fracturing process, and the microseismic event distribution results are shown in Figure 12 and Table 2. During the fracturing stage, the geophones received 201 microseismic events, of which 125 were detected in the first rock stratum and 38 were detected in both the second and third layers.

The following conclusions are drawn from the monitoring results: the cracks formed by the first fracturing are the most ideal. For the largest number of detected microseismic events, the distribution is relatively dense and the fracture trend is essentially the same. The cracks formed by the second lamination are ideal. The scale of the formed cracks is lower than that of the first layer. The number of obtained microseismic events is very different from that of the first layer, and the distribution is relatively sparse.

According to the monitoring results, the monitoring effect of the third layer is poor, the scale of the formed cracks is the smallest, the number of obtained microseismic events is relatively small, and the crack trend is affected by the first and second layers. 




(a)

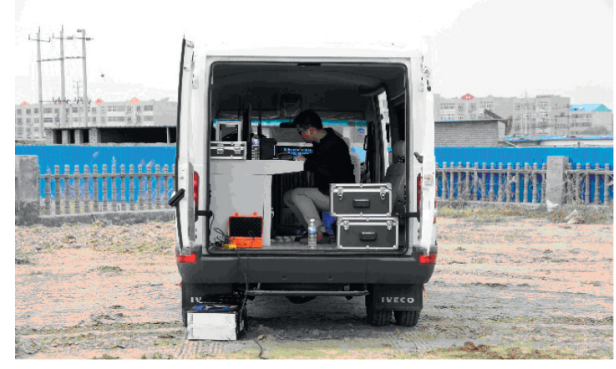

(c)

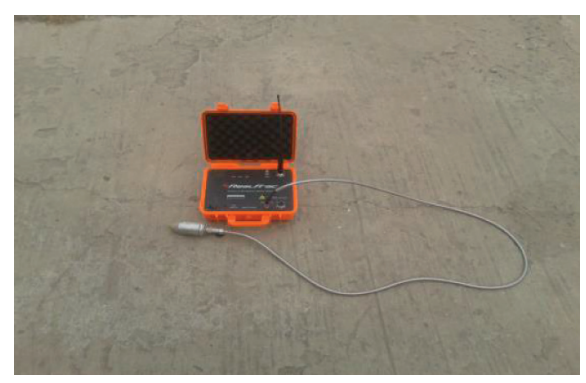

(b)

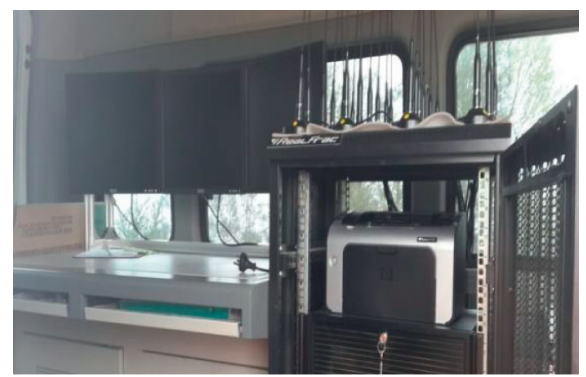

(d)

Figure 10: Microseismic monitoring equipment. (a) Monitoring station. (b) Detector. (c) Instrument car. (d) Interior of the instrument car.

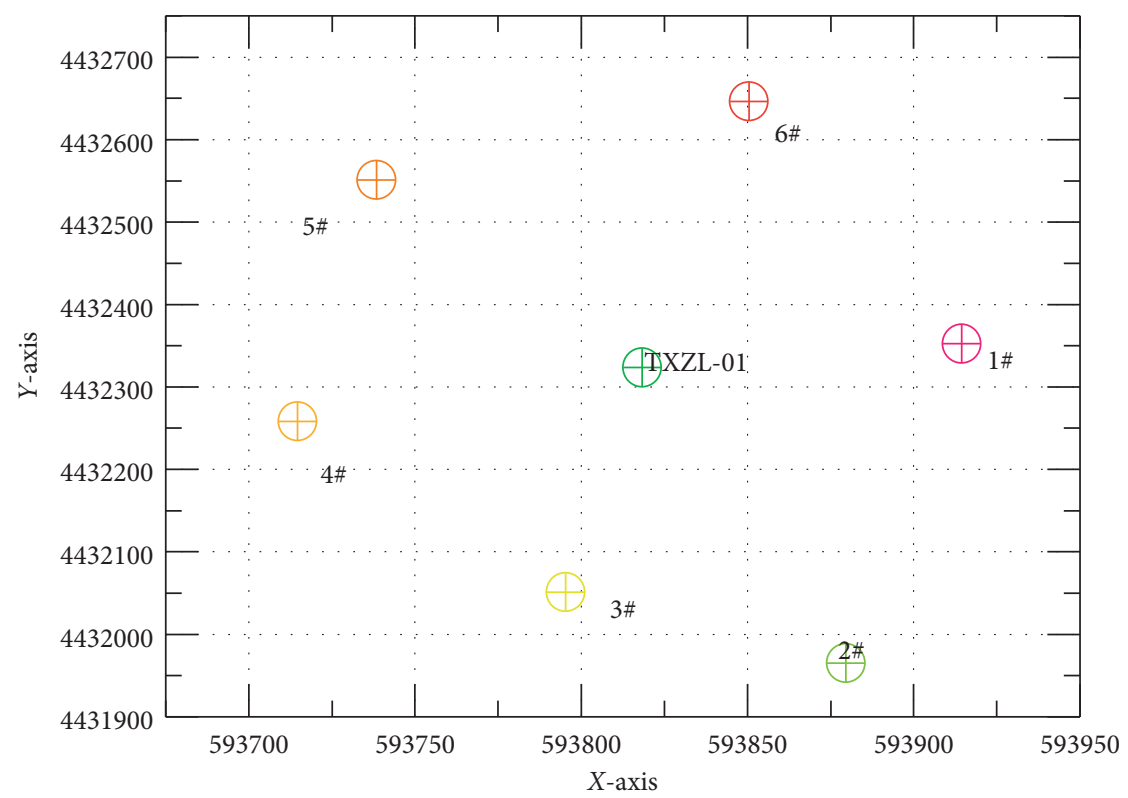

FIgURe 11: Coordinates of the station layout.

\section{Monitoring of Surrounding Rock Stress in Stopes}

After hydrofracturing, the roof rock mass strength declined due to fracture development, which further reduced the influence scope and peak intensity of lead abutment pressure. Field measurements were conducted to verify the influence of the hydrofracturing of the roof rock mass on the influence scope and peak intensity of lead abutment pressure, as shown in Figure 13.

Stations were arranged along the roadway west of the test working face, and two borehole stress meters were mounted in front of the cut-hole to monitor abutment pressure variations during mining. The $1 \#$ borehole was $130 \mathrm{~m}$ away from the cut-hole with a depth of $10 \mathrm{~m}$, and the $2 \#$ borehole was $150 \mathrm{~m}$ away from the cut-hole with a depth of $10 \mathrm{~m}$. 


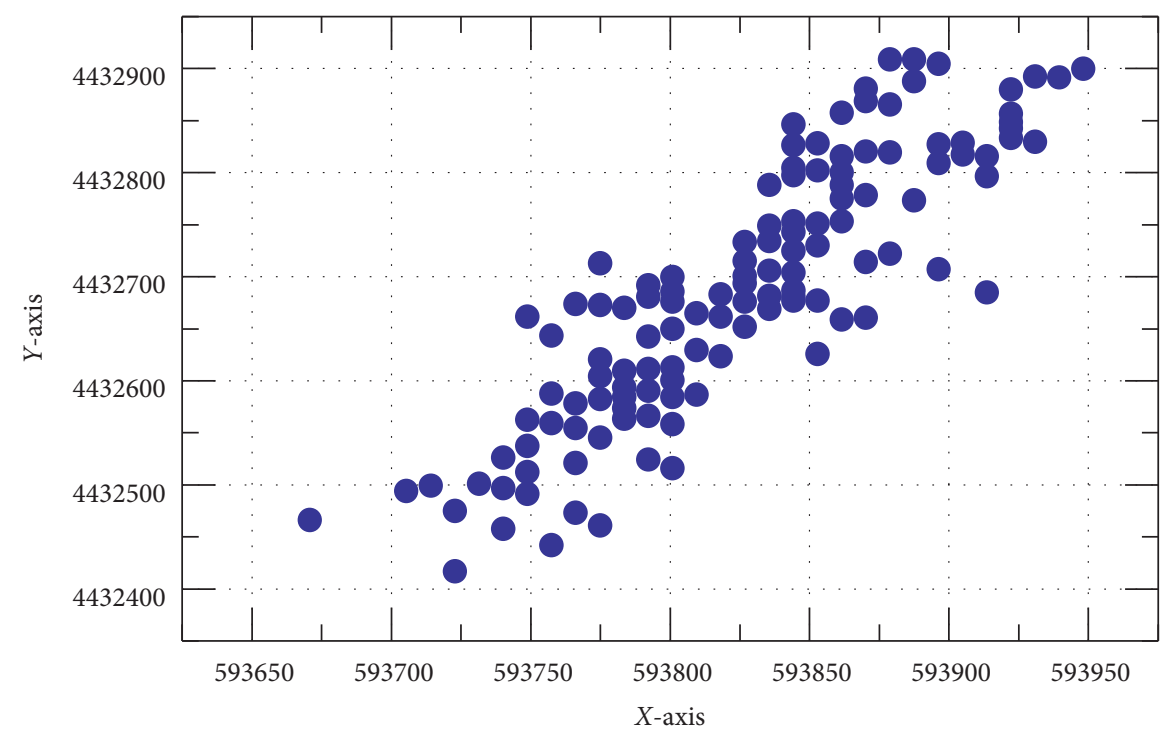

(a)

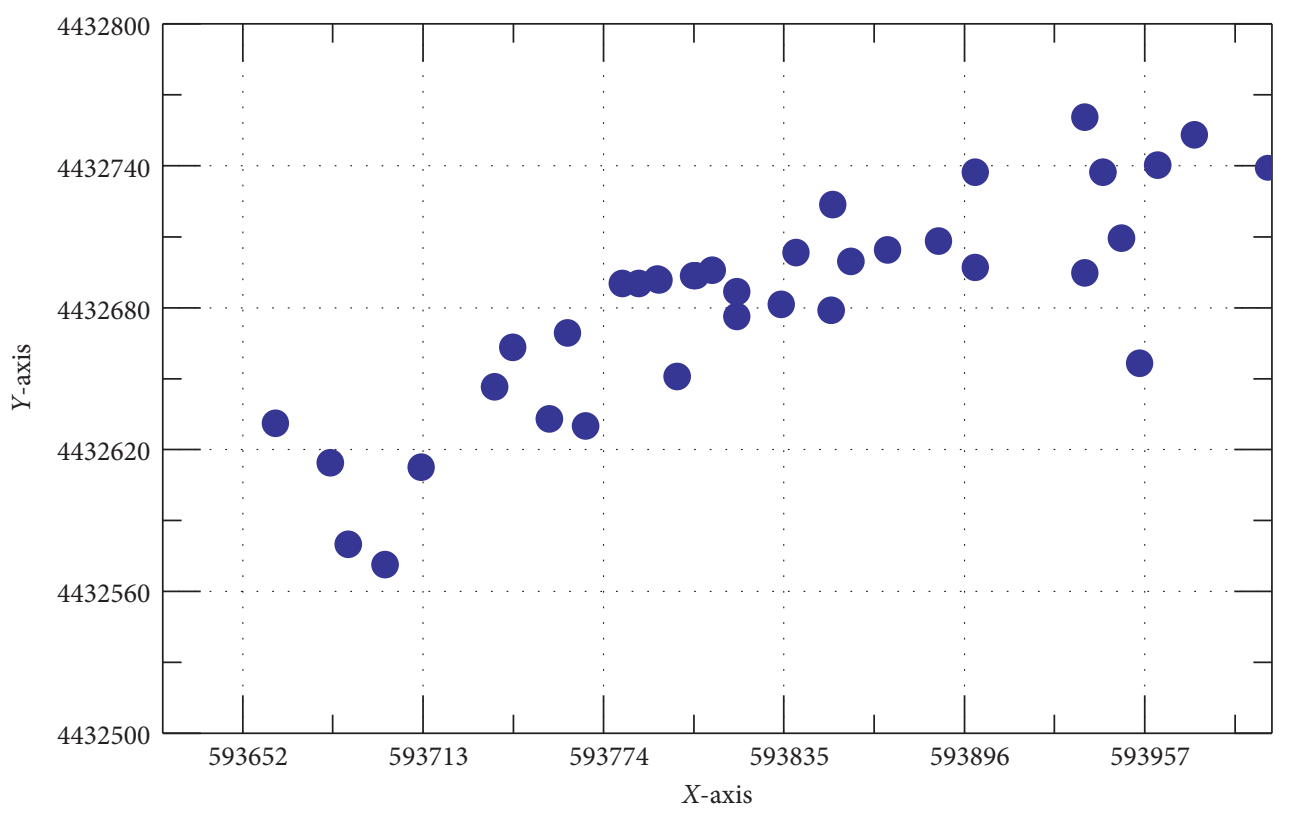

(b)

Figure 12: Continued. 


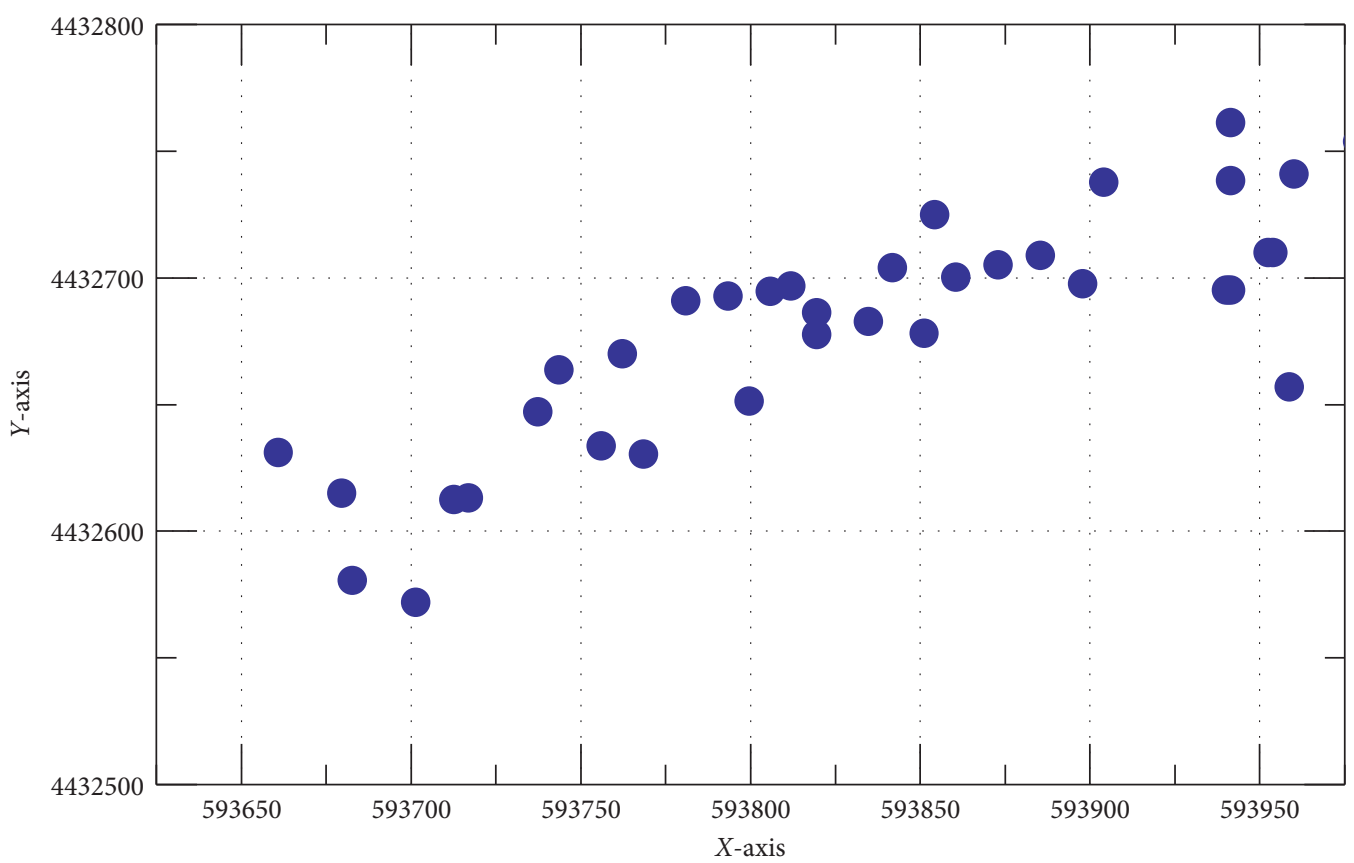

(c)

Figure 12: Monitoring results. (a) Distribution of microseismic events in the first stratum. (b) Distribution of microseismic events in the second stratum. (c) Distribution of microseismic events in the third stratum.

TABLE 2: Monitoring results for the TXZL-01 well.

\begin{tabular}{|c|c|c|c|c|}
\hline \multicolumn{2}{|l|}{ Fracture data } & $\begin{array}{c}\text { First stratum }(\mathrm{m}) \\
389.9-398.2\end{array}$ & $\begin{array}{c}\text { Second stratum }(\mathrm{m}) \\
378.35-387.85 \\
\end{array}$ & $\begin{array}{c}\text { Third stratum }(\mathrm{m}) \\
348.00-365.05\end{array}$ \\
\hline \multirow{3}{*}{ Crack length $(\mathrm{m})$} & Left wing crack length & 122 & 86 & 136 \\
\hline & Right wing crack length & 140 & 67 & 152 \\
\hline & Total length & 262 & 133 & 288 \\
\hline & 8.4 & 8 & 8 \\
\hline \multicolumn{2}{|l|}{ Fracture direction $\left({ }^{\circ}\right)$} & $\mathrm{NE} 60^{\circ}$ & NE26 & Left wing NW $100^{\circ}$, Right wing NE $10^{\circ}$ \\
\hline \multicolumn{2}{|l|}{ Crack occurrence } & Vertical & Vertical & Vertical \\
\hline
\end{tabular}

\subsection{Distribution Law of Leading Bearing Pressure after} Cracking. Considering the significant data fluctuations from the borehole stress meters due to the influence of mining activity disturbances, the average value of all the monitoring data from the stress meters from a single working day was adopted as the pressure for a given day; in combination with the working face advance distance and the mounting positions of borehole stress meters on that day, the correlation between the pressure of borehole stress meters and the working face advance distance was obtained. Figure 14(a) and 14(b) shows the borehole stress value monitoring curves of $1 \#$ station and $2 \#$ station.

In the initial monitoring stage, there was no influence from lead abutment pressure, so the stress remained stable. When the working face advanced to $80 \mathrm{~m}$ on average away from boreholes, the boreholes began to deform due to abutment pressure and borehole stress meters began to record pressure. As the working face advanced, abutment pressure presented a slow wavelike rise. When the working face advanced to $47.8 \mathrm{~m}$ away from 1 \# borehole and $50.5 \mathrm{~m}$ away from 2\# borehole, the borehole stress meters displayed a significant pressure increase, suggesting that the stations had entered the influence scope of lead abutment pressure in which case they were $49.15 \mathrm{~m}$ on average away from the working face. When the working face was respectively $15.9 \mathrm{~m}$ and $11.7 \mathrm{~m}$ away from $1 \#$ and 2\# stations, abutment pressure reached its peak, with peak stresses of $17.85 \mathrm{MPa}$ and $19.32 \mathrm{MPa}$, respectively, in which case the working face was $13.8 \mathrm{~m}$ on average away from the stations.

5.2. Distribution Law of Leading Bearing Pressure before Cracking. To evaluate the influence of hydrofracturing on lead abutment pressure, the 8201 working face, whose geological conditions are similar to those of test working face, was selected for investigation. At the same time, several strong ground pressure events occurred in the adjacent working face of the mining area [25]. Figure 15 shows lead abutment pressure monitoring results for the 8201 working face.

As can be seen from Figure 15, when no roof hydrofracturing was conducted, the significant influence distances of lead abutment pressure for the 8201 working face were $61.1 \mathrm{~m}$ 


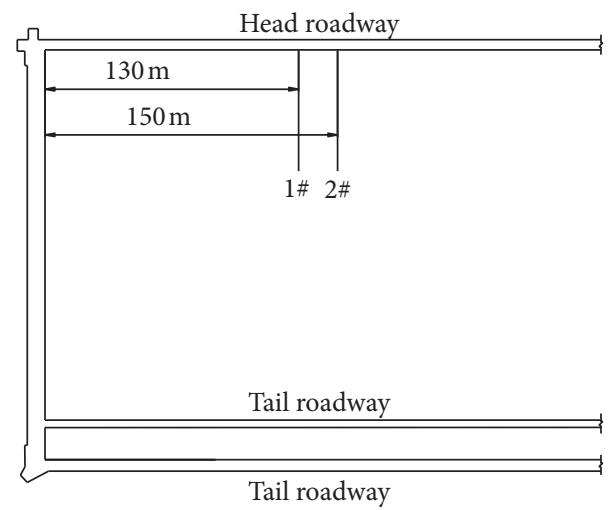

FIgURE 13: Schematic diagram of the station layout.

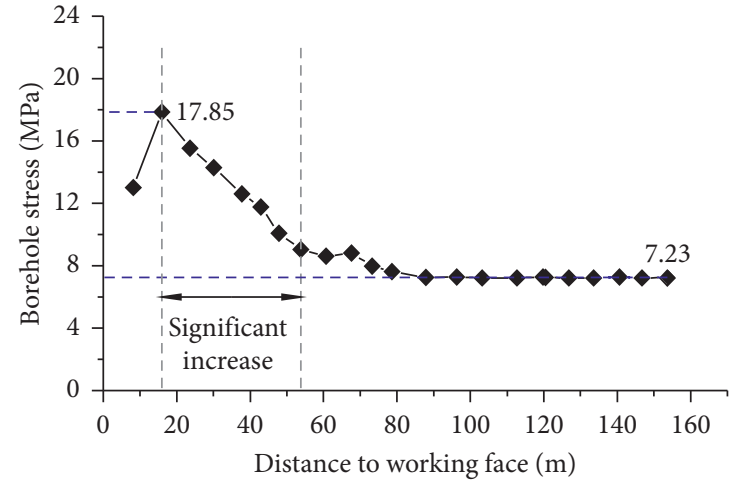

(a)

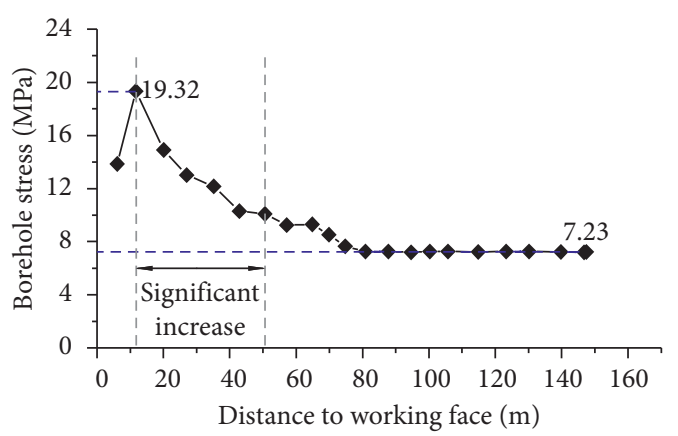

(b)

Figure 14: Lead abutment pressure monitoring results. (a) 1\# Borehole. (b) 2\# Borehole.

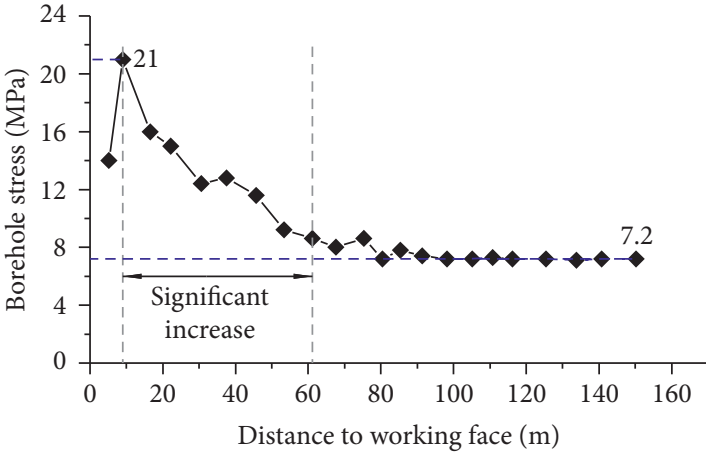

(a)

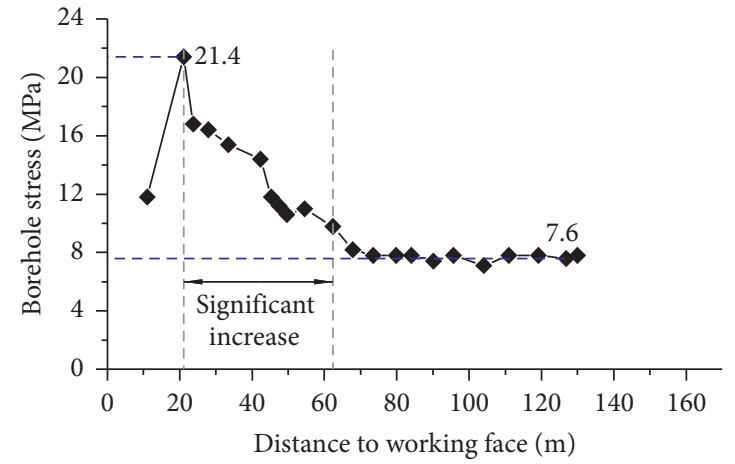

(b)

FIGURE 15: Lead abutment pressure monitoring results. (a) 1\# Borehole. (b) 2\# Borehole.

and $62.3 \mathrm{~m}(61.7 \mathrm{~m}$ on average), respectively, and lead abutment pressure peaks were $21 \mathrm{MPa}$ and $21.4 \mathrm{MPa}(21.2 \mathrm{MPa}$ on average), respectively. In this case, the lead abutment pressure influence scope and peak intensity were significantly greater than that when hydrofracturing was used.

Seen from lead abutment pressure distribution rules, after hydrofracturing the cut-hole roof strata, the lead abutment pressure influence scope reduced to $49.15 \mathrm{~m}$, which was $15.85 \mathrm{~m}$ less than in the numerical simulation and $12.55 \mathrm{~m}$ less than without hydrofracturing. Meanwhile, lead abutment pressure peaks were less than those in the theoretical calculation and numerical simulation and were only 18.58 MPa on average, which was 2.62 MPa less than without hydrofracturing. Being significantly lower than original lead abutment pressure, it reserved a sufficient margin for the mining period. 


\section{Conclusion}

The findings of this study are as follows:

(1) Theoretical calculation and numerical analysis were performed to investigate the stress distribution law of the surrounding rock in a coal seam stope. The results reveal that the surrounding rock is affected by the hard roof. The surrounding rock affected by the concentrated stress has a large range, and this can easily cause the occurrence of strong mine pressure disasters.

(2) Surface fracturing well technology can effectively crack the hard roof of a coal seam, and in combination with technology for the microseismic monitoring of the fracturing well, it can effectively evaluate and guide the fracturing work. According to the monitoring results, the hydraulic fracturing forms a crack with a more consistent trend inside the hard rock stratum, which has a better effect on roof fracturing.

(3) The on-site monitoring results reveal that after hydraulic fracturing, the influence range of the support pressure was $49.15 \mathrm{~m}$ and the peak value of the advance support pressure was reduced to $18.58 \mathrm{MPa}$. Compared with the state before the fracturing measures in the mining area, a substantial reduction was achieved. The results reveal that the hydraulic fracturing of the roof effectively reduces the impact of the stope's surrounding rock stress on production.

\section{Data Availability}

The data used to support the findings of this study are available from the corresponding author upon request.

\section{Conflicts of Interest}

There are no conflicts of interest.

\section{Acknowledgments}

The research was supported by the Datong Basic Research Project (2019122) and Scientific and Technological Innovation Programs of Higher Education Institutions in Shanxi (2019L0754).

\section{References}

[1] R. Singh, T. N. Singh, and B. B. Dhar, "Coal pillar loading in shallow mining conditions," International Journal of Rock Mechanics and Mining Sciences and Geomechanics Abstracts, vol. 33, no. 8, pp. 757-768, 1996.

[2] J. H. Wang, "Key technology for fully-mechanized top coal caving with large mining height in extra-thick coal seam," Journal of China Coal Society, vol. 38, no. 12, pp. 67-70, 2013.

[3] R. Singh, "Staggered development of a thick coal seam for full height working in a single lift by the blasting gallery method," International Journal of Rock Mechanics and Mining Sciences, vol. 41, no. 5, pp. 745-759, 2004.

[4] A. Jaiswal and B. K. Shrivastva, "Stability analysis of the proposed hybrid method of partial extraction for underground coal mining," International Journal of Rock Mechanics and Mining Sciences, vol. 52, pp. 103-111, 2012.

[5] Z. Z. Huang, "Three plies in top coal theory and its application in top coal caving mining for ultra-thick coal seams," Journal of China Coal Society, vol. 42, no. 4, pp. 809-816, 2017.

[6] F. F. Wu, J. X. Yang, and B. Yu, "Determination of the roof caving heights of thick and extra thick coal seams," Journal of China University of Mining and Technology, vol. 43, no. 5, pp. 765-772, 2014.

[7] L.-M. Dou, Z.-L. Mu, Z.-L. Li, A.-Y. Cao, and S.-Y. Gong, "Research progress of monitoring, forecasting, and prevention of rockburst in underground coal mining in China," International Journal of Coal Science and Technology and Technology, vol. 1, no. 3, pp. 278-288, 2014.

[8] J. Fan, J. Chen, and D. Jiang, "A stress model reflecting the effect of the friction angle on rockbursts in coal mines," Geomechanics and Engineering, vol. 18, no. 1, pp. 21-27, 2019.

[9] J. Wang, B. Yu, H. Kang et al., "Key technologies and equipment for a fully mechanized top-coal caving operation with a large mining height at ultra-thick coal seams," International Journal of Coal Science and Technology, vol. 2, no. 2, pp. 97-161, 2015.

[10] S. H. Yan, "Theory study on the load on support of long wall with top coal caving with great mining height in extra thick coal seam," Journal of China Coal Society, vol. 34, no. 5, pp. 590-593, 2009.

[11] S. K. Das, "Observations and classification of roof strata behaviorover long-wall coalmining panels in India," International Journal of Rock Mechanics and Mining Sciences, vol. 37, no. 4, pp. 585-597, 2000.

[12] J. L. Xu and J. F. Ju, "Structural morphology of key stratum and its influence on strata behaviors in fully-mechanized face with super-large mining height," Chinese Journal of Rock Mechanics and Engineering, vol. 30, no. 8, pp. 547-556, 2011.

[13] Y.-P. Wu, P.-S. Xie, S.-G. Ren, and R.-B. Li, "Three-dimensional strata movement around coal face of steeply dipping seam group," Journal of Coal Science and Engineering (China), vol. 14, no. 3, pp. 352-355, 2008.

[14] J. C. Wang and J. S. Fang, "The uncertainty of the mining engineering and its application," International Journal of Coal Science and Technology, vol. 2, pp. 1-8, 2000.

[15] J. C. Wang and Z. H. Wang, "Impact effect of dynamic load induced by roof in high-intensity mining face," Chinese Journal of Rock Mechanics and Engineering, vol. 34, no. S2, pp. 3987-3997, 2015.

[16] S. Zhu, Y. Feng, and F. Jiang, "Determination of abutment pressure in coal mines with extremely thick alluvium stratum: a typical kind of rockburst mines in China," Rock Mechanics and Rock Engineering, vol. 49, no. 5, pp. 1943-1952, 2016.

[17] Y. Yang, Y. Ma, C. Ji, T. Kang, and X. Guo, "Effect of mining thickness on overburden movement and underground pressure characteristics for extrathick coal seam by sublevel caving with high bottom cutting height," Advances in Civil Engineering, vol. 2018, Article ID 6871820, 15 pages, 2018.

[18] Y. K. Yang, T. H. Kang, and Z. Y. Chai, "In-situ ecological construction technology in desert open-pit mining area," Environmental Engineering and Management Journal, vol. 12, no. 9, pp. 1803-1806, 2013.

[19] W. Wang, "A analytical model for cover stress re-establishment in the goaf after longwall caving mining," Journal of the Southern African Institute of Mining and Metallurgy, vol. 117, no. 7, pp. 670-683, 2017.

[20] G. X. Xie, K. Yang, and Q. M. Liu, "Study on distribution laws of stress in inclined coal pillar for fully-mechanized top-coal 
caving face," Chinese Journal of Rock Mechanics and Engineering, vol. 25, no. 3, pp. 545-549, 2006.

[21] Z. Li, S. Yu, W. Zhu et al., "Dynamic loading induced by the instability of voussoir beam structure during mining below the slope," International Journal of Rock Mechanics and Mining Sciences, vol. 132, Article ID 104343, 2020.

[22] T. Kuang, Z. Li, W. Zhu et al., "The impact of key strata movement on ground pressure behaviour in the Datong coalfield," International Journal of Rock Mechanics and Mining Sciences, vol. 119, pp. 193-204, 2019.

[23] L. Zhu, Q. Yao, Z. Xia, W. Wang, and x. Li, "Study on the movement characteristics of the overlying stratum and surrounding rock control in ultraclose coal seams: a case study," Energy Science and Engineering, vol. 8, no. 4, pp. 1231-1246, 2020.

[24] F. Cui, C. Jia, and X. Lai, "Study on deformation and energy release characteristics of overlying strata under different mining sequence in close coal seam group based on similar material simulation," Energies, vol. 12, no. 23, p. 4485, 2019.

[25] K. Ma, F. Yuan, D. Zhuang, Q. Li, and Z. Wang, "Study on rules of fault stress variation based on microseismic monitoring and numerical simulation at the working face in the dongjiahe coal mine," Shock and Vibration, vol. 2019, Article ID 7042934, 12 pages, 2019.

[26] B. Yu, W. B. Zhu, and Z. Li, "Mechanism of the instability of strata structure in far field for super-thick coal seam mining," Journal of China Coal Society, vol. 43, no. 9, pp. 2398-2407, 2018. 